Korkmaz et al, Determining Control Strategies for Damage Tolerance of an Active Tensegrity Structure, Engineering Structures, Volume 33, Issue 6, June 2011, Pages 1930-1939, doi: http://dx.doi.org/10.1016/j.engstruct.2011.02.031

\title{
Determining Control Strategies for Damage Tolerance of an Active Tensegrity Structure
}

\author{
Sinan Korkmaz, Nizar Bel Hadj Ali and lan F.C. Smith* \\ Applied Computing and Mechanics Laboratory \\ Swiss Federal Institute of Technology (EPFL) \\ ENAC/IIC/IMAC, Station 18, 1015 Lausanne, Switzerland \\ *Corresponding Author, Phone: +41 2169352 42; Fax: +41 2169347 48; Email: ian.smith@epfl.ch
}

\begin{abstract}
Tensegrity structures are spatial, reticulate and lightweight systems composed of struts and cables. Stability is provided by a self-stress state between tensioned and compressed elements. Tensegrities have received interest among scientists and engineers in fields such as architecture, civil and aerospace engineering. Flexibility and ease of tuning make these systems attractive for controllable and adaptive structures. However, tensegrities are often prone to difficulties associated with meeting serviceability criteria and with providing adequate damage tolerance when used as civil engineering structures. This paper extends research on active control of tensegrity structures to study self-repair of a tensegrity pedestrian bridge that is damaged. Selfrepair is intended to meet safety and serviceability requirements in case of cable damage in the pedestrian bridge. Intelligent control methodologies that implement stochastic search with active member grouping are proposed. Case studies for several damage scenarios are presented to show the effectiveness of the methodology. Results from simulated damage scenarios show that self-repair can be successfully performed with a minimum number of active members leading to reductions in control complexity.
\end{abstract}

Keywords: tensegrity structures, active control, self-repair, damage tolerance, stochastic search

\section{Introduction}

Recent advances in theory and practice of active structural control technology have modified the general perception of structural behavior. Through addition of sensors, actuators and computing methods, active structures can become capable of interacting with complex environments [1]. The aim of such structures is to enhance structural performance by sensing changes in behavior and in loading, adapting the structure to meet goals, and retrieving past events to improve future performance [2]. 
Korkmaz et al, Determining Control Strategies for Damage Tolerance of an Active Tensegrity Structure, Engineering Structures, Volume 33, Issue 6, June 2011, Pages 1930-1939, doi: http://dx.doi.org/10.1016/j.engstruct.2011.02.031

In built environments, structural control has been proposed for enhancing safety of structures under extreme conditions since the last quarter of the 20th century. Control of civil engineering structures was first introduced by Yao [3] as a means of protecting tall buildings against high winds. A modern concept of an active structure was proposed by Soong and Manolis [4], who described an active structure as one consisting of two types of load-resisting members: static (passive) members and dynamic (active) members. Long-term reliability of control systems has been a matter of controversy in the case of actively controlled civil structures. Structural control has been employed for earthquake protection in the US and Japan, where earthquakes are a primary concern [5]. However, many engineers believe that active control is not the best way to protect civil engineering structures against phenomena that have long return periods because of questionable long-term reliability of active control systems [6]. Instead, actively controlled structures are more suited to satisfy serviceability criteria in changing environments [2].

Since tensegrity structures can be equipped with active control systems, they have the potential to be actively controlled for safety and serviceability purposes. Tensegrity structures are spatial reticulate systems that are composed of struts and cables. Stability is provided by the self-stress state between tensioned and compressed elements independently of all external actions. Tensegrities have applications in a range of fields such as sculpture, architecture, aerospace engineering, civil engineering, marine engineering and biology [7]. Most studies found in the literature investigated form-finding [8-12] and design characteristics of tensegrity structures [13-16]. Statics and dynamics of simple tensegrity modules have also been investigated [17-19].

Research into active control of tensegrity structures was initiated in the mid-1990s. Tensegrity structures have several promising properties. A high strength to mass ratio provides possibility of designing strong and lightweight structures. Tensegrities are attractive solutions for controllable and smart structures as often small amounts of energy are needed to change the shape of tensegrity structures [20]. Djouadi et al. [21] developed an active control methodology for vibration damping of tensegrity structures intended to spatial applications. Chan et al [22] presented an experimental study of active vibration control of a three-stage tensegrity structure using local feedback control. Vibration control is also investigated by Ganesh Raja and Narayanan [23] on a two-module tensegrity structure equipped with piezoelectric actuators. Averseng and Crosnier [24] experimentally studied the control of a tensegrity plane grid where an actuation system is connected to the supports.

Fest et al. [25] experimentally explored shape-control of a five-module active tensegrity structure. A quasi-static control strategy based on stochastic search is first proposed to satisfy serviceability criterion [6]. The control strategy is then extended to take into account additional robustness objectives [26] and to perform vibration control [27]. Kanchanasaratool and Williamson [28] used active struts to perform feedback shape-control for a simple tensegrity module. 
Korkmaz et al, Determining Control Strategies for Damage Tolerance of an Active Tensegrity Structure, Engineering Structures, Volume 33, Issue 6, June 2011, Pages 1930-1939, doi: http://dx.doi.org/10.1016/j.engstruct.2011.02.031

Deployment of tensegrity structures has also been investigated. Tibert and Pellegrino [29] experimentally investigated use of telescopic struts for the deployment of tensegrity reflectors. Sultan and Skelton [30] proposed a cable-control deployment strategy for tensegrity structures. Actuators are used to modify cable lengths such that the structure is stable throughout the deployment process. Pinaud et al. [31] implemented cable-control deployment of a small-scale two-module tensegrity structure. Smaili and Motro [32] also used a cable control strategy to investigate folding of a double layer tensegrity grid by activating finite mechanisms. Korkmaz et al. [33] studied active control system configuration of a tensegrity bridge.

In most research studies into active tensegrity structures, actuation is performed through changing element lengths. Length changes can be made to struts or cables through various actuation strategies. However, strut-based actuation, employing telescopic struts, may be inefficient when required element-length changes are large. On the other hand, cable control is more complicated than strut control due to additional mechanical devices [34].

The disadvantage of controlling too many cable elements can be overcome by connecting several cables together and using only one motor to control them [35]. This suggests that groups of individual active cable elements could be combined into continuous cables. A single continuous cable can slide over multiple nodes through frictionless pulleys. Moored and BartSmith investigated actuation on a simple tensegrity beam with groups of individual active cable elements that are combined into continuous cables. Bel Hadj Ali et al. [36] proposed a modified dynamic relaxation algorithm for static analysis of tensegrity structures including continuous cables. Apart from the numerical example presented in [36,37], no study addressing structural control employing continuous cables for large tensegrity structures is available in the literature.

Flexibility makes tensegrity structures prone to difficulties associated with meeting serviceability criteria. Since structural integrity is achieved through self-stress, damage tolerance needs to be studied. Thus, damage tolerance and self-repair of tensegrities is an emerging research area. Few researchers have studied damage tolerance and self-repair of tensegrity structures through active control. Ben Kahla and Moussa [38] numerically investigated the effect of a sudden rupture of a cable on tensegrity systems. Adam and Smith [39] addressed damage location in situations of partially defined damage and self-repair of a full-scale active tensegrity structure. Abedi and Shekastehband [40] studied the structural integrity of a double layer tensegrity grid subject to member loss. Although these studies showed that tensegrity structures are often damage tolerant, no demonstration of self-repair capabilities of a tensegrity-based bridge structure could be found. Moreover, none of the previous studies compared active control strategies for the purpose of self-repair.

This study investigates self-repair opportunities for an active tensegrity pedestrian bridge for cases of cable damage. Only functional repair is addressed [41]. Self-repair actions thus aim to bring the bridge back to a serviceable state if it is damaged. Cable damage is simulated by taking 
Korkmaz et al, Determining Control Strategies for Damage Tolerance of an Active Tensegrity Structure, Engineering Structures, Volume 33, Issue 6, June 2011, Pages 1930-1939,

doi: http://dx.doi.org/10.1016/j.engstruct.2011.02.031

cable members out of the structural analysis model. As formulated in this study, the self-repair task includes a finite number of continuous variables. The size of the solution space is large $\left(1.34 * 10^{71}\right.$ possible solutions). The self-repair task is thus too complex to be modeled completely and the solution space includes local minima for this structure. Therefore classical optimization techniques cannot be applied effectively. Optimally directed solutions for changes in element lengths are identified using a stochastic search algorithm called Probabilistic Global Search Lausanne (PGSL) [42] and a gradient-based search method. The PGSL technique is based on the assumption that sets of better solutions are more likely to be found in the neighborhood of sets of good solutions and, therefore, search is intensified in regions that contain sets of good values. Search is driven by probability density functions. Case studies for several damage scenarios are presented to show the effectiveness of the methodology.

This paper describes a study of the feasibility of self-repair using discontinuous and continuous cables, an evaluation of actuation lengths using two search strategies and a comparison of element sizes required for the two control strategies. In order to achieve these objectives, first, design characteristics of the tensegrity bridge are explained. Secondly, structural behavior of the bridge in damage cases is given. Next, self-repair methodologies are proposed. Finally, effectiveness of the active control strategies are compared in terms of actuation length required and number of actuators needed in order to implement each strategy for self-repair purposes.

\section{Tensegrity bridge}

Design of this bridge has been presented in detail in [13]. This section is a summary of this work. A side view of the tensegrity bridge is given in Figure 1. The bridge was composed of four ringshaped tensegrity modules spanning $20 \mathrm{~m}[16,43]$. Symmetry about midspan was obtained by mirroring two modules. The structure was designed to have $2.0 \mathrm{~m}$ width internal space for walking and a clearance of $2.5 \mathrm{~m}$ as recommended by codes [44]. The dimensions of the free space were fixed to have enough room for non-motorized traffic (pedestrians and cyclists). The nodes of the bridge structure at both extremities were attached to a steel frame, which was rigidly anchored to the ground (Figure 1). Although this study focuses on this configuration, the bridge was intended to be deployable from both supports, meeting in the middle.

The pentagon module contained 15 nodes describing 3 pentagonal layers (Figure 2). The middle pentagonal-layer nodes were twisted with respect to outer pentagon by $36^{\circ}$ in the counterclockwise direction. The pentagon module comprised 15 struts held together in space by 30 cables forming a ring shaped tensegrity unit [45]. Struts could be categorized into diagonal and intermediate struts based on their position. Diagonal struts connected outer and inner pentagon nodes while intermediate struts connected middle pentagon nodes to outer and inner pentagon nodes. Similarly, cables were separated into 10 layer cables and $20 \mathrm{x}$-cables. Layer cables connected nodes of the two outer pentagons while $\mathrm{x}$-cables connected middle pentagon nodes to inner and outer pentagon nodes. The $10 \mathrm{x}$-cables that were coplanar with the diagonal 
Korkmaz et al, Determining Control Strategies for Damage Tolerance of an Active Tensegrity Structure, Engineering Structures, Volume 33, Issue 6, June 2011, Pages 1930-1939,

doi: http://dx.doi.org/10.1016/j.engstruct.2011.02.031

struts were called coplanar $x$-cables. In Figure 1 and Figure 2, thick lines denote bars while thin lines denote cables.

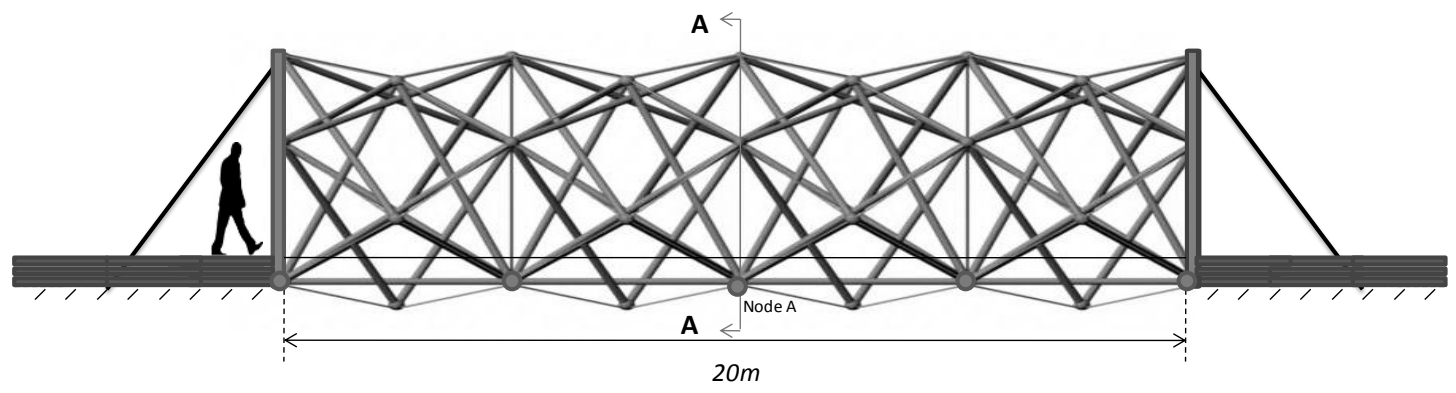

Figure 1. Tensegrity bridge

The pentagon module used in this study had a length of $500 \mathrm{~cm}$ with an inner radius of $390 \mathrm{~cm}$. This geometry satisfied internal space requirements. Diagonal and intermediate struts were chosen to have the same length of $678 \mathrm{~cm}$. Layer cables had a length of $458 \mathrm{~cm}$ while $x$-cables were $347 \mathrm{~cm}$ long. The nodes of the structure at both extremities were fixed in all three translation directions. Live loads were applied on the footbridge deck and were thus transmitted to the four bottom nodes on each module. Two of the bottom nodes were shown as Node $A$ and Node B in Figure 2. The deck was fixed to the tensegrity modules through pins at four nodes per module and therefore, it did not increase the number of independent self-stress states. Dead and wind loads were applied as nodal forces on the structure.
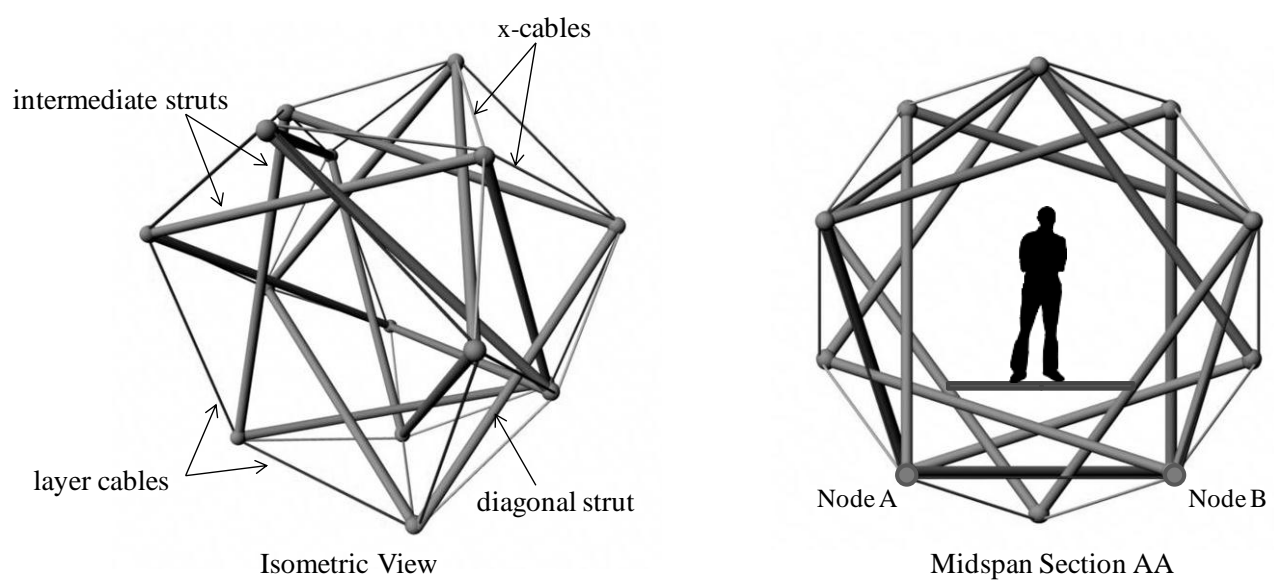

Figure 2. Pentagon module

Two configurations of the bridge were designed and studied. In the first configuration, all cable elements were assumed to be discontinuous and firmly attached to the structure nodes. In the second configuration, each sequence of four noncoplanar $x$-cables was replaced by a single 
Korkmaz et al, Determining Control Strategies for Damage Tolerance of an Active Tensegrity Structure, Engineering Structures, Volume 33, Issue 6, June 2011, Pages 1930-1939,

doi: http://dx.doi.org/10.1016/j.engstruct.2011.02.031

continuous cable that was assumed to run over frictionless pulleys connected to the nodes. The 40 noncoplanar x-cables of the tensegrity bridge were thus replaced by only ten continuous cables. As will be shown in next sections, use of continuous cables changed the static behavior of the bridge and the way it can be controlled.

The tensegrity bridge was designed to meet design specifications for safety and serviceability defined by the Swiss Code (SIA). Two load combinations were considered for Ultimate Limit State (ULS) verifications. In Equation 1 and Equation 2 dead load (G), live load (Q), loads due to self-stress (P) and wind (W) were combined to verify the overall strength and stability of the structure (Eq.1) and the local member resistance (Eq.2). The self-stress was assigned a load factor of 0.8 and 1.2 in Eq.1 and Eq.2, respectively.

$$
\begin{aligned}
& 1.35 G+1.5 Q+0.8 P+0.6 W \\
& 1.35 G+1.5 Q+1.2 P+0.6 W
\end{aligned}
$$

Under Serviceability Limit State loading (SLS), design loads are combined as follows:

$$
1.0 G+0.4 Q+1.0 P+0.6 W
$$

The coefficient related to $P$ in Eq.1 ensured that the structure was stable even with a lower level of self-stress. Similarly, the coefficient of $P$ in Eq.2 provided structural elements that resist the internal stresses when self-stress was greater than expected.

Design optimization of the tensegrity bridge was performed using member dimensions and selfstress level as design variables [43]. Struts were separated into two design groups: diagonal and intermediate struts. Strut members in each group were to have the same hollow tube section profile. Layer cables in the whole footbridge were specified to be of same section and experience the same level of self-stress. The same design decision was taken into account for $x$ cables.

As recommended by the Swiss Code, a live load of $4 \mathrm{kN} / \mathrm{m}^{2}$ has been taken into account [46]. The bridge deck was made of steel and it is assumed to have a weight of $1 \mathrm{kN} / \mathrm{m}^{2}$. The structural members have been selected from commercially available standard steel sections with specified cross-sectional profiles and cables. For struts, the product set consisted of 45 hollow-tube section profiles. The steel grade was S355, with a modulus of elasticity of $210000 \mathrm{MPa}$ and yield stress of $355 \mathrm{MPa}$. For cables, a list of 22 sections was used. Cables were made of stainless steel with a modulus of elasticity of $120000 \mathrm{MPa}$. Material properties and unit prices were obtained from major Swiss steel fabricators. Design variables included the self-stress level in the tensegrity structure. The self-stress ratio was defined as the ratio between the member pretension axial stress (before loading) and its yield (or buckling) stress. Nine discrete self-stress ratios for cables were considered running between zero and $20 \%$ in steps of $2.5 \%$. 
Korkmaz et al, Determining Control Strategies for Damage Tolerance of an Active Tensegrity Structure, Engineering Structures, Volume 33, Issue 6, June 2011, Pages 1930-1939,

doi: http://dx.doi.org/10.1016/j.engstruct.2011.02.031

Structural analyses for various load combinations were performed using dynamic relaxation [36]. Analysis results were used to check safety and serviceability requirements. A genetic algorithm (GA) was employed to solve the design optimization task since genetic algorithms are more suitable than other stochastic search methods for discrete variables (45 tube sections and 22 cable sections). Optimization variables were coded as integer strings. Penalty functions were employed to handle design constraints by penalizing individuals that violated constraints, and thus giving them a lower probability of survival. The penalty function approach was implemented by adding an additional term to the objective function. This additional term corresponded to the cost of violating constraints. In this manner, the search for optimum solutions was directed toward feasible regions of the search space. Optimization results were satisfactory for a population size of 50 individuals running for 60 generations. Crossover and mutation probabilities were fixed as 0.9 and 0.1 , respectively. The best solution generated over a sequence of five runs using different random seeds is taken to be the optimal design solution.

\section{Two cable-configuration designs}

For the bridge configuration having discontinuous cables, the optimal design attained after five runs of the GA has a cost of CHF41,100. The material cost is calculated using estimates of Swiss market values of the materials used. Node fabrication costs, although likely to be high, are not included because this cost is used for comparison only with other designs having the same topology (number of nodes). Member sections and self-stress ratios for the design solution are displayed in Table 1. The self-stress ratio is defined in Section 2. While imposed on cables as design specifications, the values for the struts are calculated values.

Under the SLS load combination, midspan displacement should not exceed $2.8 \mathrm{~cm}$ (span length/700). For the as-designed configuration, the maximum midspan displacement is $2.7 \mathrm{~cm}$. The design is governed by serviceability criteria. Table 2 provides a comparison of stresses due to factored loads with strength values for struts and cables. Under ULS load combination, a maximum axial compression force of $41 \mathrm{kN}\left(30 \mathrm{~N} / \mathrm{mm}^{2}\right)$ is obtained in struts, which represents $50 \%$ of buckling capacity. Maximum tension forces of $63 \mathrm{kN}\left(356 \mathrm{~N} / \mathrm{mm}^{2}\right)$ and $19 \mathrm{kN}\left(374 \mathrm{~N} / \mathrm{mm}^{2}\right)$ are obtained for $\mathrm{x}$-cables and layer cables respectively. Tension forces in $\mathrm{x}$-cables and layer cables represent $33 \%$ and $35 \%$ of their yield capacities respectively.

Table 1. Design results for the bridge with discontinuous cables

\begin{tabular}{lccc}
\hline Member & Diameter $[\mathrm{mm}]$ & Cross-sectional area $\left[\mathrm{mm}^{2}\right]$ & Self-stress ratio [\%] \\
\hline Diagonal struts & 114 & 1390 & 13 \\
Intermediate struts & 114 & 1390 & 13 \\
Layer cables & 8 & 50 & 13 \\
X-cables & 15 & 177 & 8 \\
\hline
\end{tabular}


Korkmaz et al, Determining Control Strategies for Damage Tolerance of an Active Tensegrity Structure, Engineering Structures, Volume 33, Issue 6, June 2011, Pages 1930-1939, doi: http://dx.doi.org/10.1016/j.engstruct.2011.02.031

Table 2. ULS Code verification for the bridge with discontinuous cables

\begin{tabular}{lcc}
\hline Member & $\begin{array}{c}\text { Maximum Stress }\left[\mathrm{N} / \mathrm{mm}^{2}\right] \\
\text { (due to factored loads) }\end{array}$ & $\begin{array}{c}\text { Tensile or Buckling Strength }\left[\mathrm{N} / \mathrm{mm}^{2}\right] \\
\text { (with resistance factor) }\end{array}$ \\
\hline Diagonal Struts & 30 & 60 \\
Intermediate Struts & 30 & 60 \\
Layer cables & 374 & 1069 \\
X-cables & 356 & 1069 \\
\hline
\end{tabular}

For the bridge configuration with continuous cables, an optimum design resulting in a material cost of CHF49,800 is obtained by using GA-based optimization. Table 3 gives the member sections and self-stress ratios for structural members. Under the SLS load combination, the maximum displacement of the two midspan nodes is $2.8 \mathrm{~cm}$.

Under ULS load combinations, a maximum axial compression force of $58 \mathrm{kN}\left(34 \mathrm{~N} / \mathrm{mm}^{2}\right)$ is obtained in diagonal struts and this represent $39 \%$ of buckling capacity. Intermediate struts have a maximum compression value of $51 \mathrm{kN}\left(37 \mathrm{~N} / \mathrm{mm}^{2}\right)$ representing $62 \%$ of their buckling capacity. Maximum tension forces of $37 \mathrm{kN}\left(401 \mathrm{~N} / \mathrm{mm}^{2}\right)$ and $102 \mathrm{kN}\left(594 \mathrm{~N} / \mathrm{mm}^{2}\right)$ are obtained for layer cables and $\mathrm{x}$-cables respectively. Tension forces in layer cables and $\mathrm{x}$-cables represent $56 \%$ and $38 \%$ of their tension capacities (Table 4 ). In the bridge with continuous cables, the buckling strength of the diagonal struts differ from the buckling strength of the diagonal struts in the bridge configuration with discontinuous cables (Table 2 and Table 4) since the diameters of are different (Table 1 and Table 3).

Table 3. Design results for the bridge with continuous cables

\begin{tabular}{lccc}
\hline Member & Diameter $[\mathrm{mm}]$ & Cross-sectional area $\left[\mathrm{mm}^{2}\right]$ & Self-stress ratio [\%] \\
\hline Diagonal struts & 140 & 1710 & 18 \\
Intermediate struts & 114 & 1390 & 45 \\
Layer cables & 9 & 63.6 & 20 \\
X-Cables & 18 & 254.5 & 20 \\
\hline
\end{tabular}

Table 4. ULS Code verification for the bridge with continuous cables

\begin{tabular}{lcc}
\hline Member & $\begin{array}{c}\text { Maximum Stress }\left[\mathrm{N} / \mathrm{mm}^{2}\right] \\
\text { (due to factored loads) }\end{array}$ & $\begin{array}{c}\text { Tensile or Buckling Strength }\left[\mathrm{N} / \mathrm{mm}^{2}\right] \\
\text { (with resistance factor) }\end{array}$ \\
\hline Diagonal Struts & 34 & 87 \\
Intermediate & 37 & 60 \\
Layer cables & 594 & 1069 \\
X-cables & 401 & 1069 \\
\hline
\end{tabular}


Korkmaz et al, Determining Control Strategies for Damage Tolerance of an Active Tensegrity Structure, Engineering Structures, Volume 33, Issue 6, June 2011, Pages 1930-1939, doi: http://dx.doi.org/10.1016/j.engstruct.2011.02.031

For the two configurations of the bridge, optimization results show that the design of the bridge is governed by SLS requirements. Added flexibility induced by the use of continuous cables result in a design solution with higher levels of self-stresses. Furthermore, cross-sectional areas of diagonal struts, layer cables and $\mathrm{x}$-cables are larger in the bridge configuration having continuous cables while cross-sectional areas of intermediate struts remain the same in both configurations.

\section{Bridge behavior after damage}

Structural behavior of the two configurations is analyzed using the dynamic-relaxation method [47]. Cable damage is simulated by taking cable members out of the structural analysis model. Under ULS load combination, all stresses are below the limits for all simulated cases. Therefore, safety requirements are met when the structure is damaged.

Structural integrity can be lost for several reasons, such as cases of accidental damage and element removal during maintenance. In this study, the aim of the active control system is to maintain serviceability when cable damage (or removal) occurs. While safety criteria are based on stress limits, the serviceability criterion refers to deflection limitations for this study. Nodal displacements and stresses in the structural elements are computed under several load combinations determined by design specifications [44].

Results show that there is symmetry between the effects of damage when cables that are similarly positioned in the two halves of the bridge are damaged. Thus, the results obtained by damage in only Module 1 and Module 2 are discussed (Figure 3). Position and numbering of damaged cables are shown in Figure 3. Damage is simulated for the layer cables that belong to the intermediate and middle pentagons as well as for the $\mathrm{x}$-cables of the first and the second modules of the structure. In the configuration that has continuous cables, the number of damage cases is reduced compared to that of the bridge configuration having discontinuous cables. 
Korkmaz et al, Determining Control Strategies for Damage Tolerance of an Active Tensegrity Structure, Engineering Structures, Volume 33, Issue 6, June 2011, Pages 1930-1939, doi: http://dx.doi.org/10.1016/j.engstruct.2011.02.031

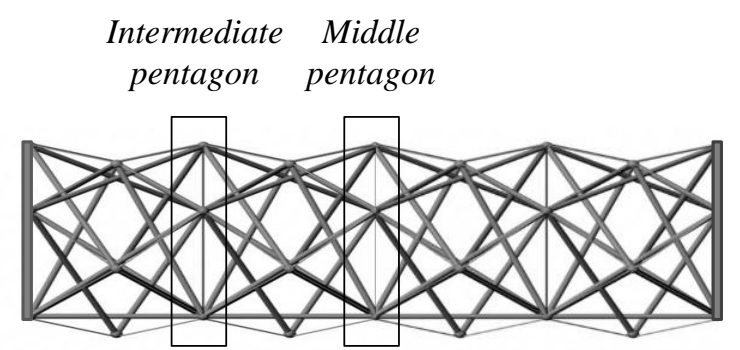

Module 1 Module 2 Module 3 Module 4

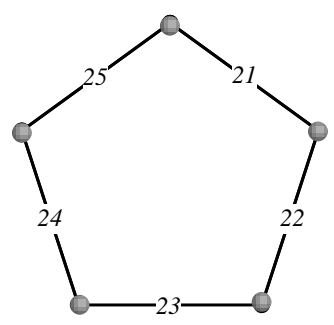

Intermediate pentagon

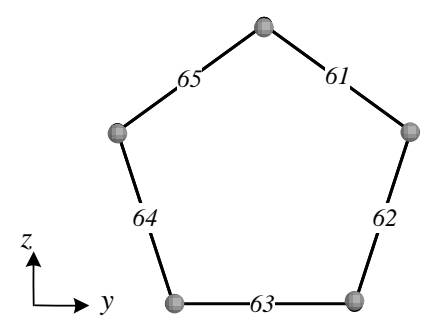

Middle pentagon

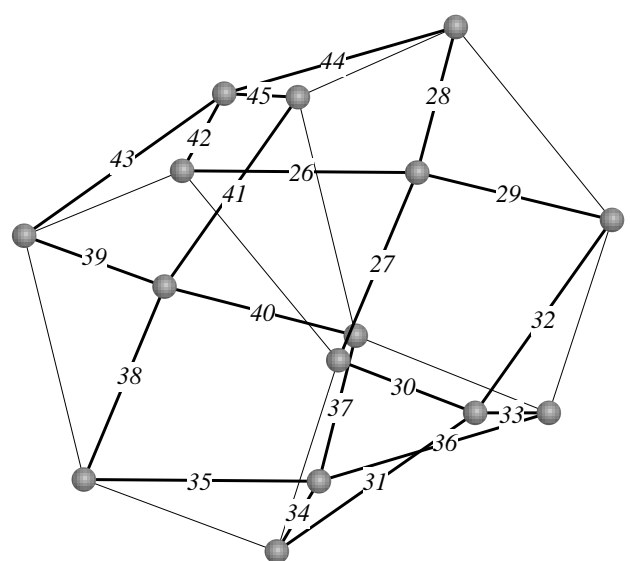

Module 1

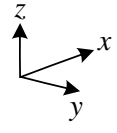

西

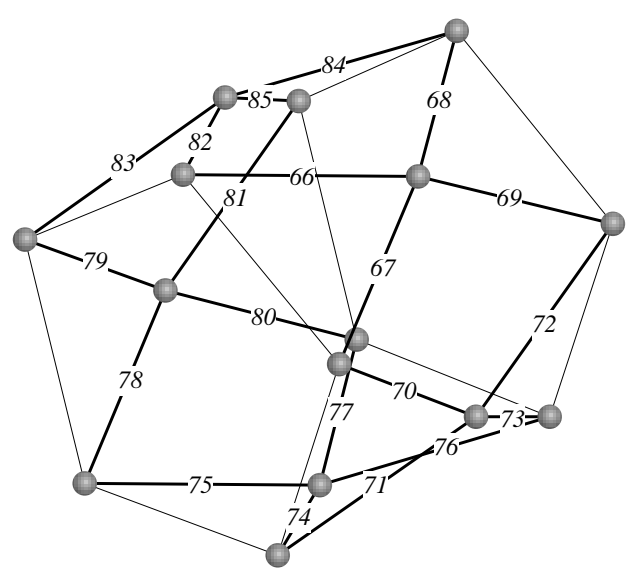

Module 2

Figure 3. Side view of the tensegrity bridge with numbering of cables of the two first modules

Figure 3 shows cable members of the first and the second module of the bridge. Each of the two pentagonal layers (i.e. intermediate pentagon and middle pentagon) involves 5 layer cables. There are 10 discontinuous $x$-cables and 5 continuous $x$-cables in each module. Damage cases of all these cables have been investigated.

Results indicate that the safety requirements are met for all cases of individual cable damage. That is, effects of the loading in the structural members (i.e. stresses) are smaller than the ultimate strength (including buckling strength) of the members in damage cases. However, this is not the case for serviceability requirements. Figures 4-9 show the displacements at the two midspan nodes (Node A and Node B, Figures 1-2) for all possible single cable damage cases. Results show that the vertical displacements at bridge midspan exceed the limit $(2.8 \mathrm{~cm}$, span length/700) for certain damage cases. Simulation results indicate that the structural behavior varies with the position of the damaged cable and that the structure is more affected by damage in a few critical cables than it is when other cables are damaged. 
Korkmaz et al, Determining Control Strategies for Damage Tolerance of an Active Tensegrity Structure, Engineering Structures, Volume 33, Issue 6, June 2011, Pages 1930-1939, doi: http://dx.doi.org/10.1016/j.engstruct.2011.02.031

\subsection{Configuration with discontinuous cables}

Figures 4-6 show the magnitudes of midspan deflections for configuration with discontinuous cables in damage cases where cables in Module 1 and Module 2 are damaged.

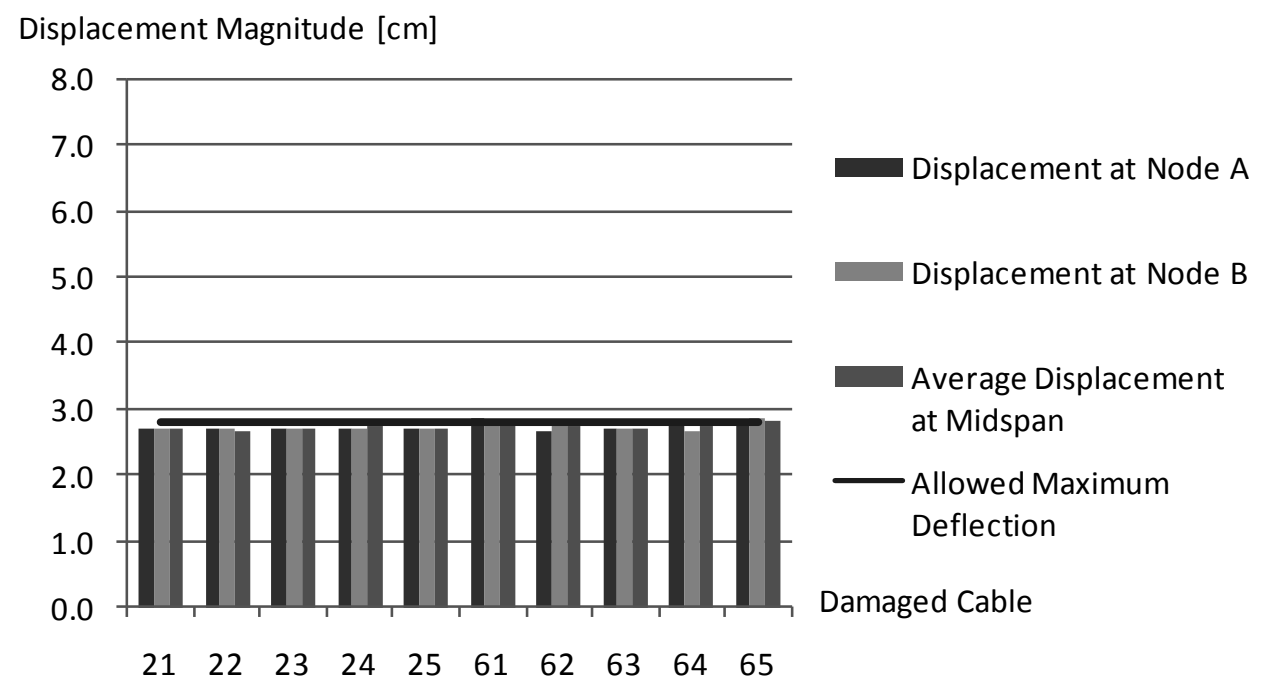

Figure 4. Midspan displacements for damage of intermediate and middle pentagon layer cables (discontinuous cables)

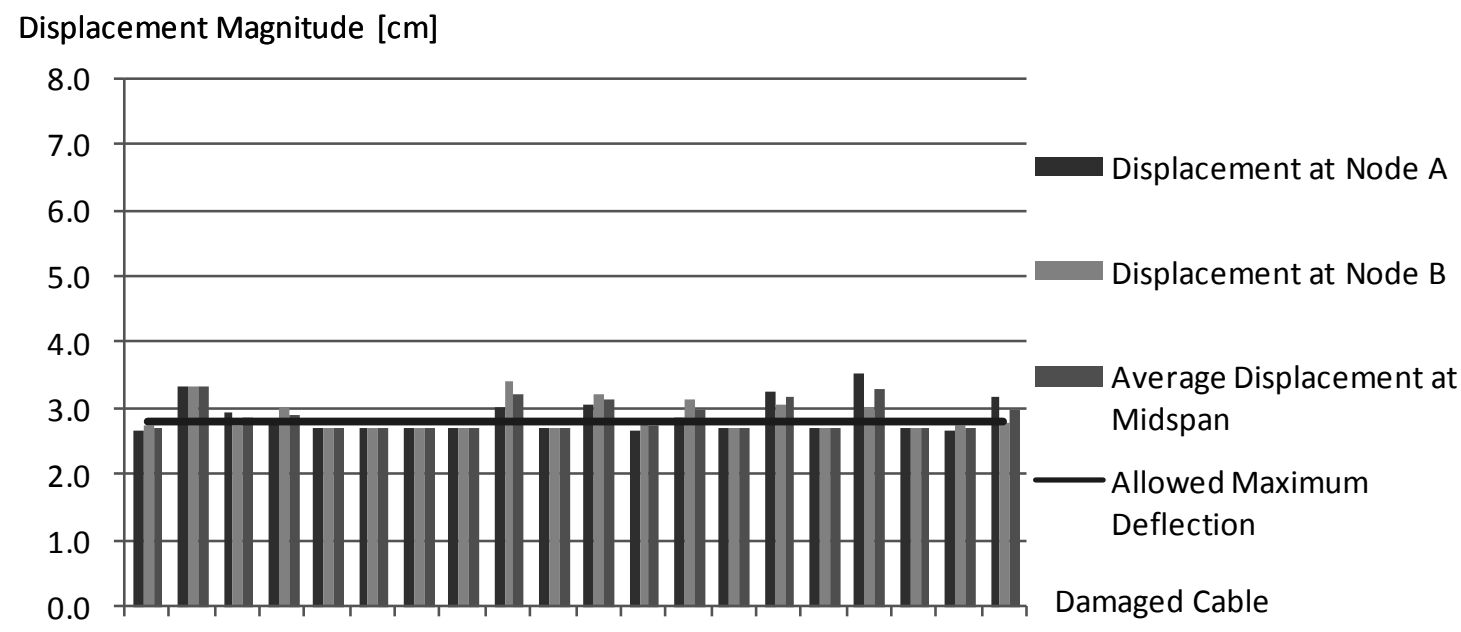

2627282930313233343536373839404142434445

Figure 5. Midspan displacements for damage of $x$-cables of the first pentagon (discontinuous cables) 
Korkmaz et al, Determining Control Strategies for Damage Tolerance of an Active Tensegrity Structure, Engineering Structures, Volume 33, Issue 6, June 2011, Pages 1930-1939, doi: http://dx.doi.org/10.1016/j.engstruct.2011.02.031

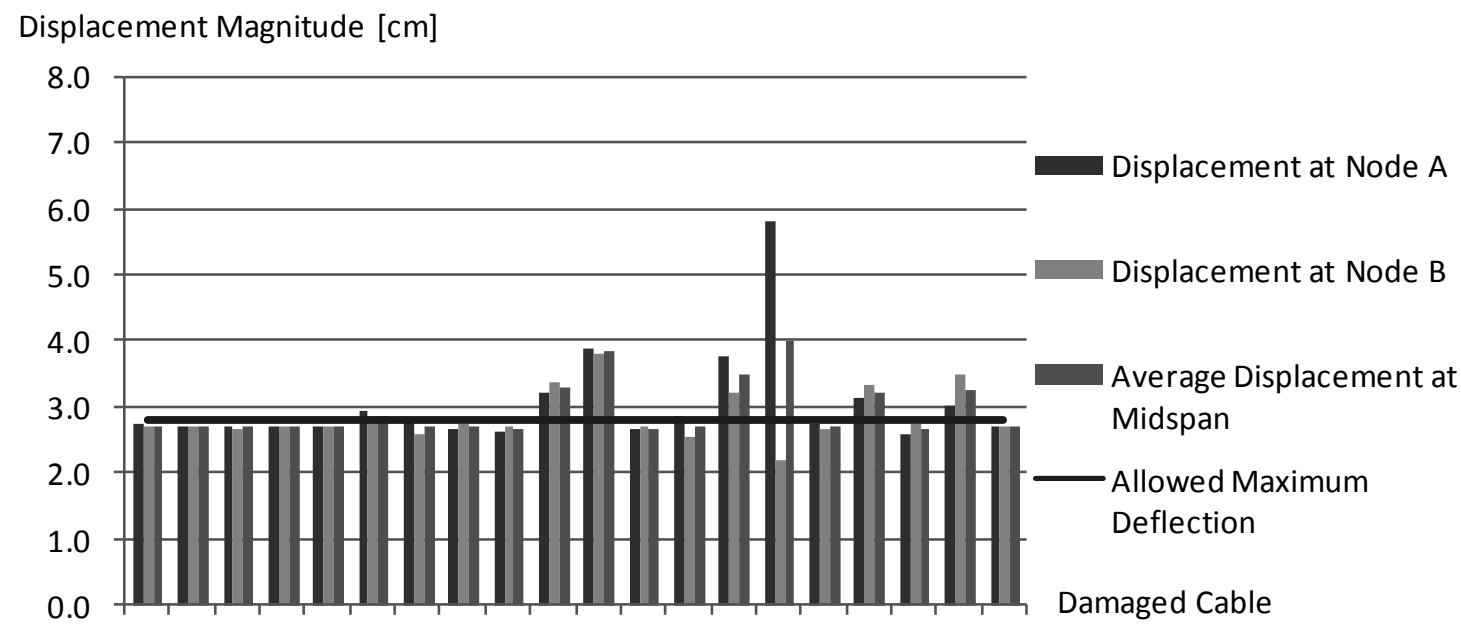

6667686970717273747576777879808182838485

Figure 6. Midspan displacements for damage of x-cables of the second pentagon (discontinuous cables)

In configuration with discontinuous cables, average displacements at midspan are below the limit for cases where layer cables are damaged (Figure 4). However, there are several x-cables where damage causes excessive displacements at midspan of the structure. A potential need for active control arises for these cases since the structure is no longer serviceable although safety criteria are satisfied (Figure 5 and Figure 6).

\subsection{Configuration with continuous cables}

Figures 7-9 show the magnitudes of midspan deflections for configuration with continuous cables for cases where cables in Module 1 and Module 2 are damaged. 
Korkmaz et al, Determining Control Strategies for Damage Tolerance of an Active Tensegrity Structure, Engineering Structures, Volume 33, Issue 6, June 2011, Pages 1930-1939, doi: http://dx.doi.org/10.1016/j.engstruct.2011.02.031

Displacement Magnitude [cm]

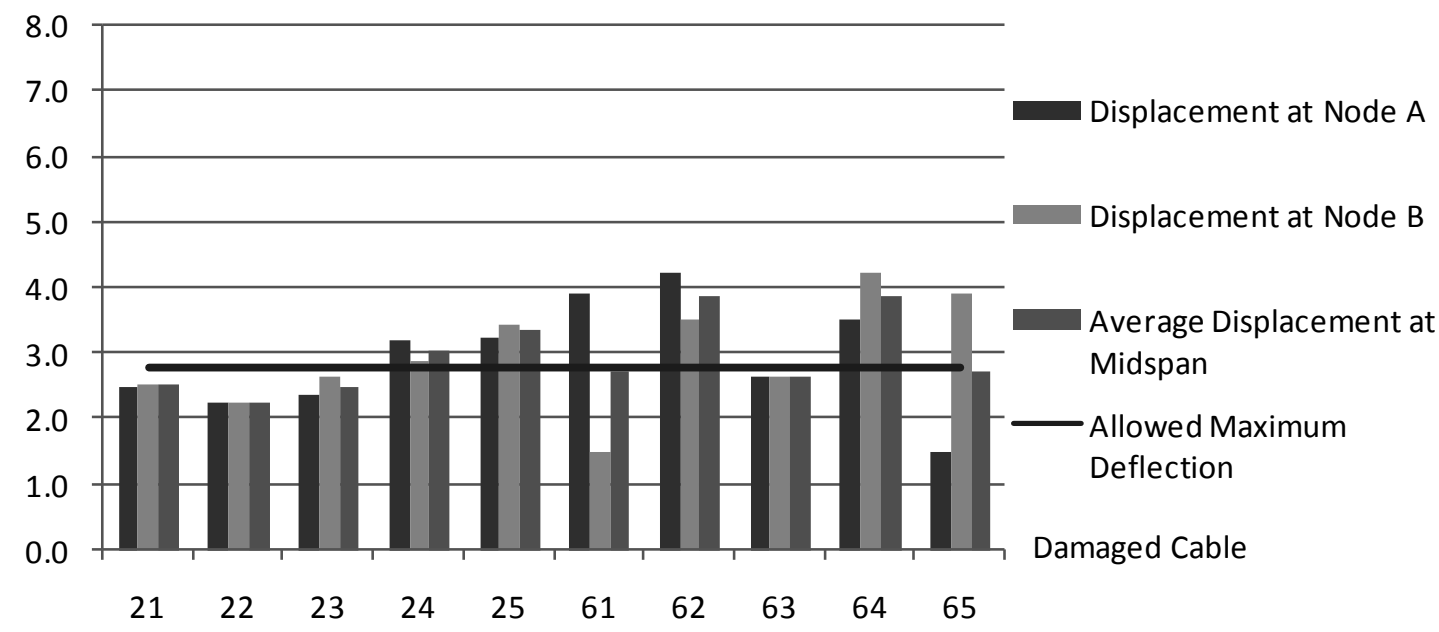

Figure 7. Midspan displacements for damage of intermediate and middle pentagon layer cables (continuous cables)

Displacement Magnitude [cm]

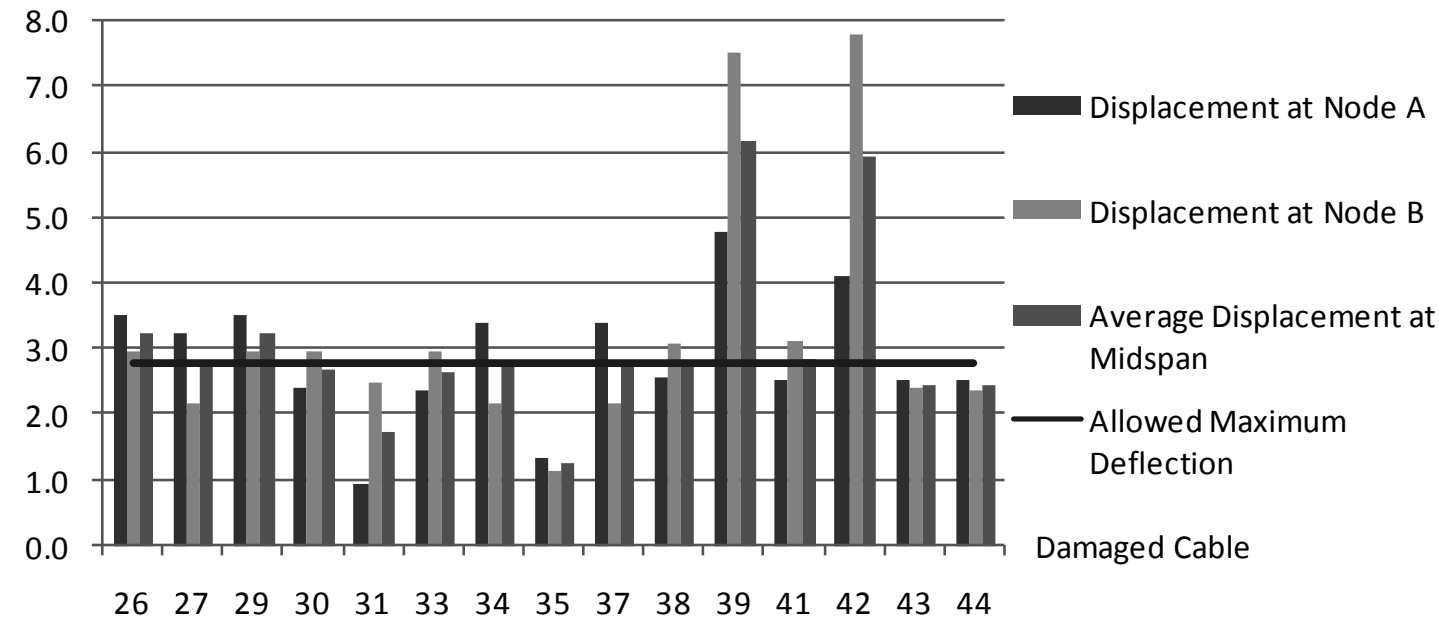

Figure 8. Midspan displacements for damage of x-cables of the first pentagon (continuous cables) 
Korkmaz et al, Determining Control Strategies for Damage Tolerance of an Active Tensegrity Structure, Engineering Structures, Volume 33, Issue 6, June 2011, Pages 1930-1939, doi: http://dx.doi.org/10.1016/j.engstruct.2011.02.031

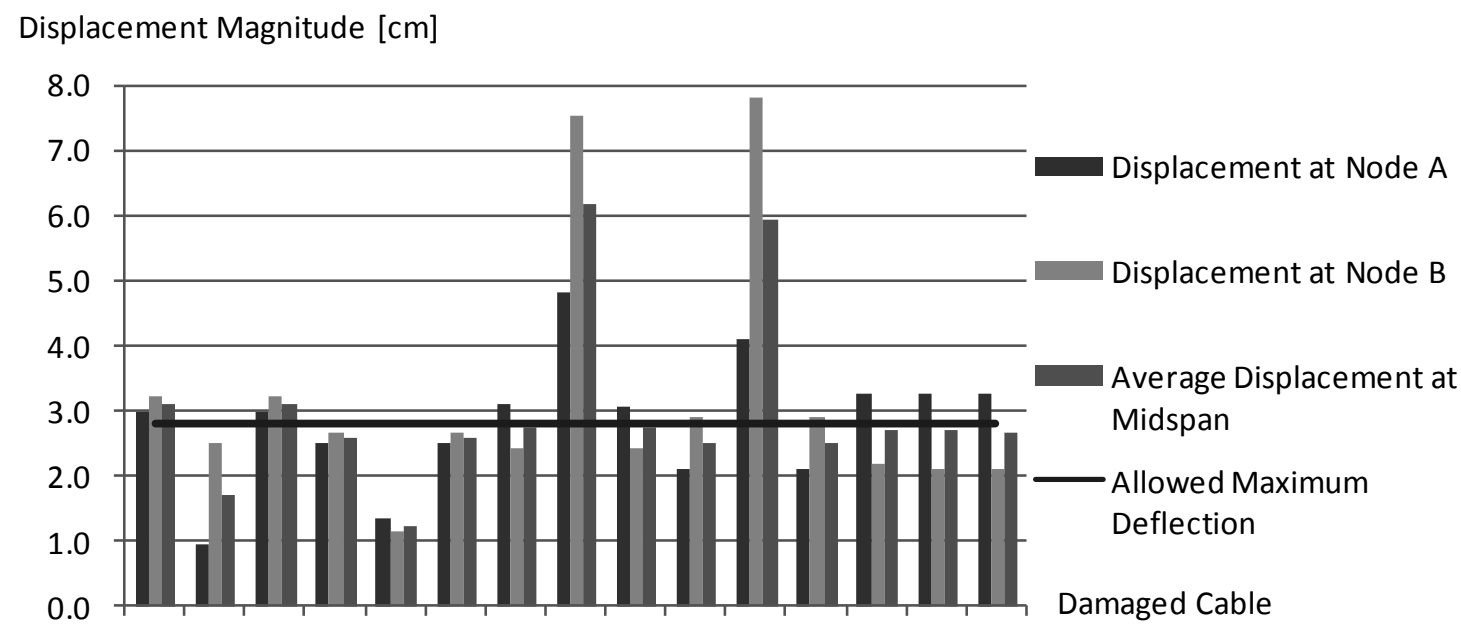

$\begin{array}{lllllllllllllll}66 & 67 & 69 & 70 & 71 & 73 & 74 & 75 & 77 & 78 & 79 & 81 & 82 & 83 & 84\end{array}$

Figure 9. Midspan displacements for damage of $x$-cables of the first pentagon (continuous cables)

Midspan displacements are higher when configuration with continuous cables replaces configuration with discontinuous cables. Damage in some layer cables result in excessive midspan displacements when configuration with continuous cables are analyzed.

\section{Damage tolerance through active control}

Critical-cable-damage cases (i.e. where damage causes the greatest deflections) are selected as case studies for self-repair. When these cables are damaged, the maximum displacement magnitudes at the midspan nodes are between $5.8 \mathrm{~cm}$ and $3.5 \mathrm{~cm}$ for the configuration having discontinuous cables and between $7.8 \mathrm{~cm}$ and $7.5 \mathrm{~cm}$ for the configuration having continuous cables. However, the displacement at bridge midspan must not exceed $2.8 \mathrm{~cm}$ (Section 3). Cables symmetric along the middle pentagon layer of the structure have the same displacement values at midspan nodes (Table 5 and Table 6).

Table 5. Greatest midspan displacements for cases of individual cable damage in the structure with discontinuous cables (Cable numbers in parentheses indicate the symmetrical cables)

\begin{tabular}{lc}
\hline Damaged Cable No. & Maximum Displacement $[\mathrm{cm}]$ \\
\hline $80(111)$ & -5.8 \\
$76(115)$ & -3.9 \\
$79(112)$ & -3.8 \\
$42(148)$ & -3.5 \\
$84(106)$ & -3.5 \\
\hline
\end{tabular}


Korkmaz et al, Determining Control Strategies for Damage Tolerance of an Active Tensegrity Structure, Engineering Structures, Volume 33, Issue 6, June 2011, Pages 1930-1939, doi: http://dx.doi.org/10.1016/j.engstruct.2011.02.031

Table 6. Greatest midspan displacements for cases of individual cable damage in the structure with continuous cables (Cable numbers in parentheses indicate the symmetrical cables)

\begin{tabular}{lc}
\hline Damaged Cable No. & Maximum Displacement $[\mathrm{cm}]$ \\
\hline $42,45,79$ and $80(111,112,147$ and 148$)$ & -7.8 \\
$39,40,75$ and $76(115,116,151$ and 152$)$ & -7.5 \\
\hline
\end{tabular}

Numerical simulations show that the tensegrity bridge is damage tolerant with respect to safety requirements. However, serviceability requirements are not satisfied in some cable damage situations. The bridge is thus not capable of accomplishing its function for some damage scenarios. Several case studies are tested numerically to show the potential of active control strategies to adjust the structural behavior to meet serviceability requirements. For a given damage scenario, the structural response may be controlled through active cable members or groups of active cables.

An objective of self-repair is to reduce excessive midspan displacements resulting from cable damage to acceptable levels with a minimum control effort. Control effort is defined by the minimum actuation length that is needed to decrease the excessive displacements to the limitation set in Section 3. An actuation scheme with minimum actuation leads to small perturbations and modest energy requirements. Active cables of the structure can be elongated or contracted modifying internal stress distribution and node displacements of the structure. The control task can thus be stated as an optimization task where the objective is to minimize the sum of active-cable length adjustments.

Let $\mathbf{x}^{\mathbf{t}}=\left[x_{1}, x_{2}, \ldots, x_{N A G}\right]$ be the vector of actuation length for all active group of members. The damage-tolerance control task can be stated as follows:

$\min f=\sum_{n=1}^{N A G}\left|x_{i}\right|$

subject to

$$
\begin{array}{ll}
\frac{N_{s d, i}}{N_{R d, i}}-1 \leq 0, \quad i=1, \ldots, N E & \\
\frac{\delta_{\text {midspan }}}{\delta_{\text {limit }}}-1 \leq 0 \\
g_{x, \max }=x_{i, \text { max }}-x_{i} \geq 0, \quad \forall i=1, \ldots, N A G \\
g_{x, \text { min }}=x_{i}-x_{i, \text { min }} \geq 0, \quad \forall i=1, \ldots, N A G
\end{array}
$$


Korkmaz et al, Determining Control Strategies for Damage Tolerance of an Active Tensegrity Structure, Engineering Structures, Volume 33, Issue 6, June 2011, Pages 1930-1939, doi: http://dx.doi.org/10.1016/j.engstruct.2011.02.031

In these equations $N A G$ and $N E$ are the number of active member groups and the number of structural elements respectively. Code limitations for stresses are set to be constraints in the optimization task. Eq. (5) defines the local capacity and buckling checks for tensioned and compressed members. $N_{s d, i}$ is the ultimate axial force of member $i$, while $N_{R d, i}$ is axial force strength of member $N_{R d}$ includes $N_{k, R d}$ for struts. Eq. (6) defines the serviceability limit-state requirement of midspan deflection, $\delta_{\text {midspan, }}$ normalized by the limit defined by SIA Code. Eq. (7) and (8) represent the constraints on the control variable values. We assume that each active cable adjustment $x_{i}$ is limited to values ranging between $x_{i, \min }$ and $x_{i, \max }$.

The number of active members and possible moves define the space of possible solutions. Even with a small number of active elements, it is impossible to generate and test every possible solution due to the combinatorial nature of the task. If the precision of the actuators is set to be $0.5 \mathrm{~mm}$, solution space includes $2.66 \times 10^{23}$ possible outcomes for one damage case when continuous cables are used and $1.34 \times 10^{71}$ outcomes when discontinuous cables are used as active members. Furthermore, the objective function likely has multiple local minima. Stochastic search is therefore useful for this situation. Stochastic methods sample the solution space using special strategies. Although there is no guaranty of reaching a global optimum, near optimal solutions are usually sufficient for control applications. This optimization task was addressed using Probabilistic Global Search Lausanne (PGSL) [42]. Results obtained via PGSL are compared to the outcomes of Gradient Search Method. Two types of control are studied: control with discontinuous cables (CDC) (Table 1) and control with continuous cables (CCC) (Table 3). All of the active cables used in CDC are discontinuous cables. On the other hand, in CCC, the active members are continuous cables that run over frictionless pulleys.

For $\mathrm{CDC}$, active cable grouping is carried out as follows:

- Group 1: Cables that are not coplanar with diagonal struts

- Group 2: Group 1 and layer cables of the first three pentagons

- Group 3: Cables that are coplanar with diagonal struts

- Group 4: Group 3 and layer cables of the last three pentagons

- Group 5: Group 1 and layer cables of the three middle pentagons

- Group 6: Group 3 and layer cables of the three middle pentagons

Cable members of the tensegrity bridge are grouped according to geometrical characteristics and requirements for deployability function of the bridge (not part of this study). For example, groups are identified based on the conclusion of previous studies that the cables that are not coplanar with diagonal struts are essential for deployment function. 
Korkmaz et al, Determining Control Strategies for Damage Tolerance of an Active Tensegrity Structure, Engineering Structures, Volume 33, Issue 6, June 2011, Pages 1930-1939, doi: http://dx.doi.org/10.1016/j.engstruct.2011.02.031

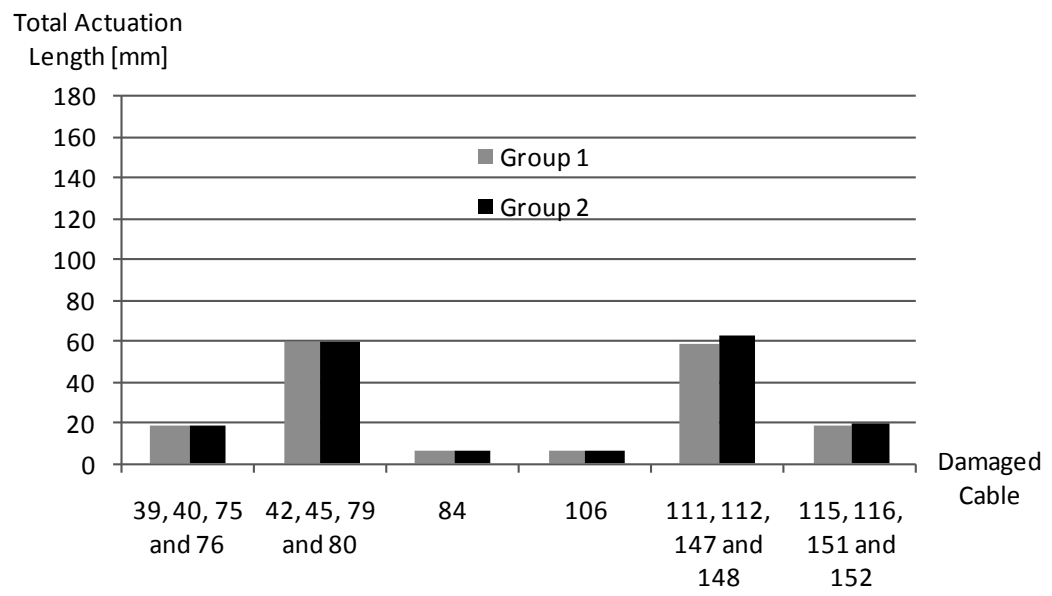

Figure 10. Actuation lengths needed to modify the structure so that deflections do not exceed $2.8 \mathrm{~cm}$ (active cable Group 1 and Group 2)

Figure 10 contains the results of calculations of total actuation lengths determined by PGSL. Six cases of damage are evaluated. In the cases where multiple cable damage is investigated, the damaged cables are selected from adjacent active cables in order to provide a comparison between CDC and CCC. Results vary from actuation lengths of $6 \mathrm{~mm}$ to $63 \mathrm{~mm}$ for the case of four cables damaged simultaneously $(111,112,147,148)$. There is no significant difference in the results for Group 1 and Group 2. Therefore, layer cables do not need to be activated for these cases. Therefore, of the two groups, Group 1 is more suitable to be active.

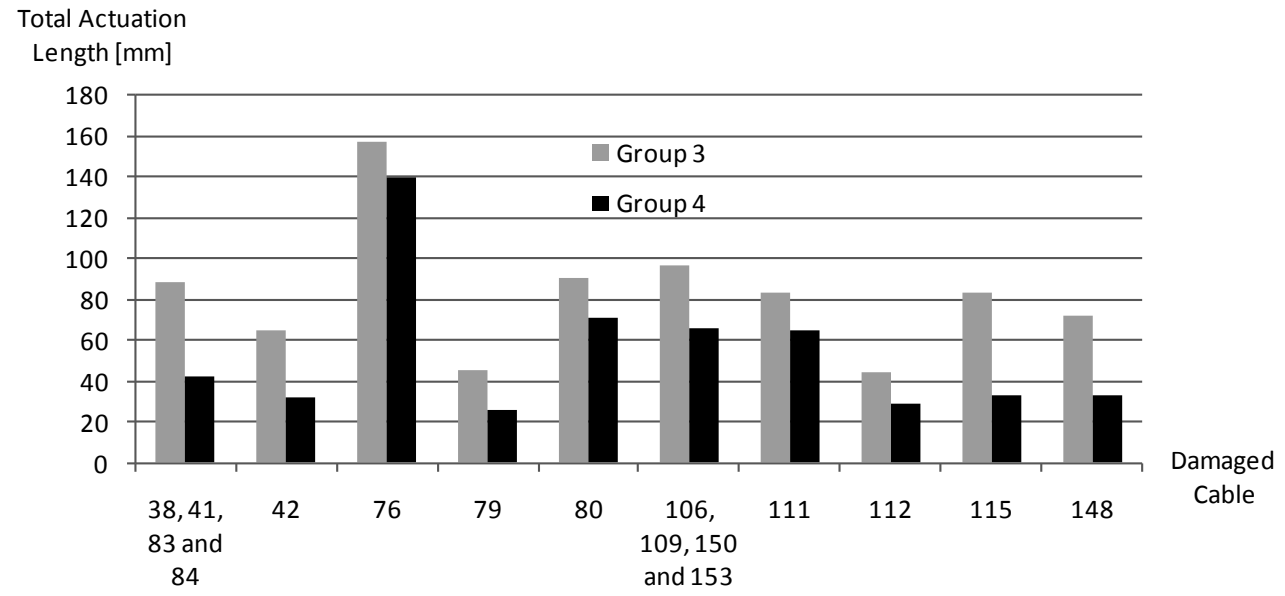

Figure 11. Actuation lengths needed to modify the structure so that deflections do not exceed $2.8 \mathrm{~cm}$ (active cable Group 3 and Group 4) 
Korkmaz et al, Determining Control Strategies for Damage Tolerance of an Active Tensegrity Structure, Engineering Structures, Volume 33, Issue 6, June 2011, Pages 1930-1939, doi: http://dx.doi.org/10.1016/j.engstruct.2011.02.031

Figure 11 presents results for ten cases of damage. In two of the cases given, where cables 38 , 41, 83 and 84 as well as cables 106, 109, 150 and 153 are damaged, all of the damaged cables are active. Results vary from a total actuation length of $25 \mathrm{~mm}$ for the case of a broken cable 79 to $158 \mathrm{~mm}$ for the case of a broken cable 76 . Controlling Group 4 consistently leads to shorter actuation lengths than for Group 3. Results indicate that activating cables of Group 1 leads to shorter actuation lengths. Therefore, Group 1 provides damage tolerance with shorter actuation lengths and a smaller number of active members.

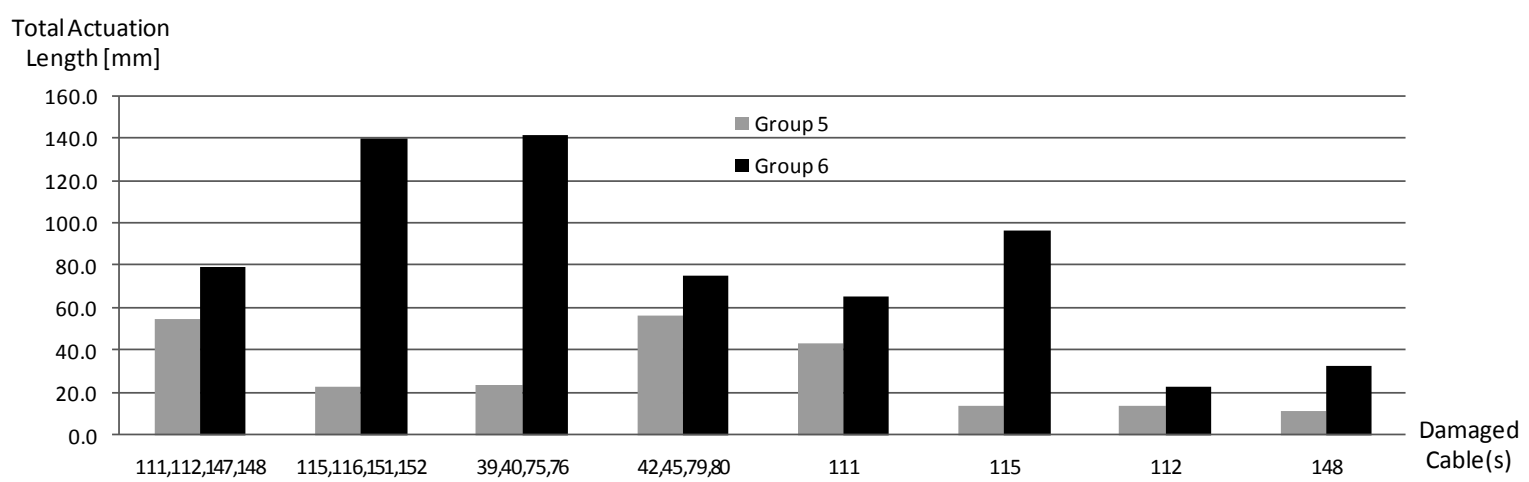

Figure 12. Actuation lengths needed to modify the structure so that deflections do not exceed $2.8 \mathrm{~cm}$ (active cable Group 5 and Group 6)

Figure 12 introduces results obtained by using Group 5 and Group 6. Although the damaged cables, which cannot be controlled, belong to Group 5 in the first four damage cases, controlling Group 5 leads to lower actuation lengths than Group 6 for every damage case.

Table 7. Minimum total actuation lengths needed for self-repair $(\mathrm{mm})$

\begin{tabular}{lcc}
\hline Damaged Cables & Group 1 & Group 5 \\
\hline $111,112,147,148$ & 58.9 & 54.3 \\
$115,116,151,152$ & 18.1 & 22.7 \\
$39,40,75,76$ & 18.3 & 23.9 \\
$42,45,79,80$ & 59.5 & 56.1 \\
\hline Total & 154.8 & 157.0 \\
\hline
\end{tabular}

Results given in Figure 10, Figure 11 and Figure 12 indicate that Group 1 and Group 5 require less total actuation length for self-repair than the other four groups. Table 7 gives actuation lengths needed for a damage tolerant structure by separately employing groups 1 and 5 . Although Group 5 involves 15 more active cables than does Group 5, total actuation lengths needed for self-repair are smaller than when Group 1 is used. 
Korkmaz et al, Determining Control Strategies for Damage Tolerance of an Active Tensegrity Structure, Engineering Structures, Volume 33, Issue 6, June 2011, Pages 1930-1939, doi: http://dx.doi.org/10.1016/j.engstruct.2011.02.031

Table 8 shows the minimum total actuation lengths needed for self-repair of the structure for critical damage cases when CDC and CCC are applied. When the same cables in the two configurations are damaged, the minimum total actuation lengths needed for self-repair are understandably higher with CCC than they are with CDC.

Table 8. Minimum total actuation lengths needed for self-repair ( $\mathrm{mm}$ )

\begin{tabular}{lcc}
\hline Damaged Cables & CDC & CCC \\
\hline $111,112,147,148$ & 54.3 & 170.6 \\
$115,116,151,152$ & 18.1 & 194.3 \\
$39,40,75,76$ & 18.2 & 194.2 \\
$42,45,79,80$ & 56.1 & 167.3 \\
111 & 43.4 & 170.6 \\
115 & 13.9 & 194.3 \\
112 & 13.7 & 170.6 \\
148 & 11.7 & 170.6 \\
42 & 31.6 & 167.3 \\
79 & 25.3 & 167.3 \\
62 & 2.0 & 78.2 \\
64 & 2.5 & 50.9 \\
\hline Total & 290.8 & 1896.2 \\
\hline
\end{tabular}

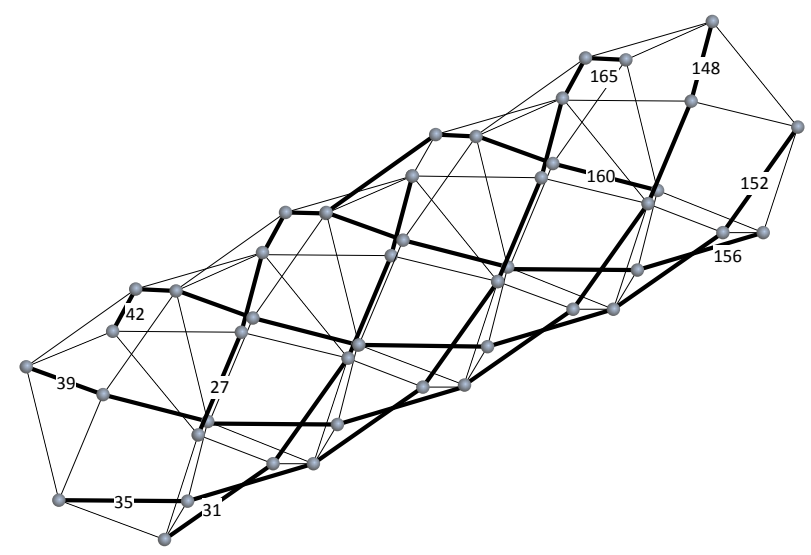

Figure 13. Active cables in Group 1 with CCC

Figure 13 illustrates the structural system of the tensegrity bridge. Thick lines show the struts and thin lines represent the cables. Black elements are active cables in Group 1 with CCC.

For CDC, a motor is needed in order to actuate each active cable while one motor is enough to actuate a cable cluster of 4 cables in CCC. For this structure, CCC provides self-repair with only 
Korkmaz et al, Determining Control Strategies for Damage Tolerance of an Active Tensegrity Structure, Engineering Structures, Volume 33, Issue 6, June 2011, Pages 1930-1939, doi: http://dx.doi.org/10.1016/j.engstruct.2011.02.031

10 actuators, while CDC requires 40 actuators (Table 9). Results given in Table 8 demonstrate that CDC requires less total actuation length for self-repair. Since continuous cables lead to higher deflections in the structure, which lead to higher levels of actuation and higher internal stresses than for discontinuous cables, cross-sectional areas and self-stress in structural members have to be increased when CCC is used (Table 1, Table 2, Table 3 and Table 4). On the other hand, results given in Table 9 indicate that CCC provides self-repair with fewer actuators than required by CDC. Therefore, actuation complexity is dramatically reduced when CCC is used. Moreover, technical difficulties associated with actuation of cables are reduced by positioning the actuators at the extremities $(X=0$ and $X=2000 \mathrm{~cm}$, Figure 13$)$ of the bridge.

Table 9. Number of actuators needed for self-repair

\begin{tabular}{lcc}
\hline & CDC & CCC \\
\hline Number of Actuators & 40 & 10 \\
\hline
\end{tabular}

Three damage scenarios are chosen considering the displacements at the midspan nodes of configuration having continuous cables. Actuation opportunities with CCC are examined by using two sampling methods: PGSL and Gradient Search Method. Single-objective search is carried out with the constraints given by Equations 2-5.

The aim of the optimization process is to minimize actuation lengths without exceeding code limitations (safety and serviceability criteria). Therefore, maximum displacement magnitude at midspan after actuation is limited to this value. Displacement magnitudes at midspan before actuation, which vary from $3.2 \mathrm{~cm}$ to $7.8 \mathrm{~cm}$ for the most critical damage cases, are successfully decreased to a maximum value of $2.8 \mathrm{~cm}$.

Table 10. Comparison of two search techniques for determining self-repair control commands

\begin{tabular}{ccccc}
\hline Damaged Cables & $\begin{array}{c}\text { Displacement Before } \\
\text { Actuation }(\mathrm{cm})\end{array}$ & $\begin{array}{c}\text { Search } \\
\text { Algorithm }\end{array}$ & $\begin{array}{c}\text { Actuation Length } \\
(\mathrm{mm})\end{array}$ & $\begin{array}{c}\text { Displacement After } \\
\text { Actuation }(\mathrm{cm})\end{array}$ \\
\hline $111,112,147,148$ & 7.8 & PGSL & 170.6 & 2.8 \\
$111,112,147,148$ & 7.8 & Gradient Search & 214.2 & 2.8 \\
$115,116,151,152$ & 7.5 & PGSL & 194.3 & 2.8 \\
$115,116,151,152$ & 7.5 & Gradient Search & 200.4 & 2.5 \\
$107,108,162,165$ & 3.2 & PGSL & 13.2 & 2.8 \\
$107,108,162,165$ & 3.2 & Gradient Search & 167.7 & 0.4 \\
\hline
\end{tabular}


Korkmaz et al, Determining Control Strategies for Damage Tolerance of an Active Tensegrity Structure, Engineering Structures, Volume 33, Issue 6, June 2011, Pages 1930-1939, doi: http://dx.doi.org/10.1016/j.engstruct.2011.02.031

One case of gradient search reduces the midspan displacement value to $0.4 \mathrm{~cm}$. While this reduction is attractive, the objective is to identify the search algorithm that satisfies code requirements using the shortest actuation length. The search algorithm, PGSL does this in all three cases, (Table 10).

\section{Conclusions and future work}

Two designs of this tensegrity bridge have damage tolerant characteristics for all scenarios of single-cable damage when equipped with an active control system.

Compared with CDC, CCC leads to larger cross-sections to satisfy design criteria. However, the decrease in actuation complexity obtained through CCC may enhance more effectively intelligent attributes of civil engineering structures. For such structures, actuation strategies are difficult to define. Tradeoffs between desirable characteristics (e.g. actuation lengths and element sizes) and degree of actuation are needed.

A comparison between CDC (control using discontinuous cables) and CCC (control using continuous cables) revealed that using CCC reduces the number of actuators needed for selfrepair of a tensegrity bridge. Of the two search strategies studied, PGSL identifies shorter actuation lengths. In the cases where the same cable damage scenarios are investigated for the two configurations, CDC provides a self-repair with smaller total actuation lengths. Greater displacements caused by continuous cables lead to greater minimum total actuation lengths needed for damage tolerance when continuous cables are used.

Since the actuators can be placed at the extremities of the structure when CCC is used, technical difficulties associated with actuation of cables are reduced. Thus, application of CCC is expected to be more suitable than CDC for large structures.

Future work involves building a methodology to select which members are active. A sensitivity analysis of key variables will be carried out. A global efficiency factor will be defined for each element under all load cases.

\section{Acknowledgements}

The authors would like to thank Prof René Motro for helpful discussions. This research was partially funded by the Swiss National Science Foundation under Grant No 20020-121552. 
Korkmaz et al, Determining Control Strategies for Damage Tolerance of an Active Tensegrity Structure, Engineering Structures, Volume 33, Issue 6, June 2011, Pages 1930-1939,

doi: http://dx.doi.org/10.1016/j.engstruct.2011.02.031

\section{References}

[1] T. T. Soong and G. P. Cimellaro, "Future directions in structural control," Structural Control and Health Monitoring, vol. 16, pp. 7-16, 2009.

[2] K. Shea, et al., "Developing intelligent tensegrity structures with stochastic search," Advanced Engineering Informatics, vol. 16, pp. 21-40, 2002.

[3] J. T. P. Yao, "Concept of structural control," ASCE Journal of the Structural Control, vol. 98, pp. 1567-1574, 1972.

[4] T. T. Soong and G. D. Manolis, "Active Structures," Journal of Structural Engineering, vol. 113, pp. 2290-2302, 1987.

[5] G. W. Housner, et al., "Structural Control: Past, Present, and Future," Journal of Engineering Mechanics vol. 123, pp. 897-971, 1997.

[6] B. Domer and I. F. C. Smith, "An Active Structure that Learns," Journal of Computing in Civil Engineering, vol. 19, pp. 16-24, 2005.

[7] R. E. Skelton and M. C. de Oliveira, Tensegrity Systems. New York: Springer, 2009.

[8] J. Y. Zhang and M. Ohsaki, "Adaptive force density method for form-finding problem of tensegrity structures," International Journal of Solids and Structures, vol. 43, pp. 5658-5673, 2006.

[9] M. Masic, et al., "Algebraic tensegrity form-finding," International Journal of Solids and Structures, vol. 42, pp. 4833-4858, 2005.

[10] Tibert, et al., "Review of Form-Finding Methods for Tensegrity Structures," International Journal of Space Structures, vol. 18, pp. 209-223, 2003.

[11] G. G. Estrada, et al., "Numerical form-finding of tensegrity structures," International Journal of Solids and Structures, vol. 43, pp. 6855-6868, 2006.

[12] L. Zhang, et al., "Form-Finding of Nonregular Tensegrity Systems," Journal of Structural Engineering, vol. 132, pp. 1435-1440, 2006.

[13] N. Bel Hadj Ali, et al., "Design optimization and dynamic analysis of a tensegrity-based footbridge," Engineering Structures, vol. 32, pp. 3650-3659, 2010.

[14] F. Fu, "Structural behavior and design methods of Tensegrity domes," Journal of Constructional Steel Research, vol. 61, pp. 23-35, 2005.

[15] H. Klimke and S. Stephan, "The making of a tensegrity tower," presented at the IASS Symposium 2004, Montpellier, 2004.

[16] R. Motro, et al., "Tensegrity Rings and the Hollow Rope," presented at the IASS Symposium, New Olympics, New Shells and Spatial Structures, Beijing, 2006.

[17] R. E. Skelton, et al., "An Introduction to the mechanics of tensegrity structures," in The Mechanical Systems Design Handbook, ed, 2000.

[18] S. H. Juan and J. M. Mirats Tur, "Tensegrity frameworks: Static analysis review," Mechanism and Machine Theory, vol. 43, pp. 859-881, 2008.

[19] J. M. Mirats Tur and S. H. Juan, "Tensegrity frameworks: Dynamic analysis review and open problems," Mechanism and Machine Theory, vol. 44, pp. 1-18, 2009.

[20] R. E. Skelton, et al., "An introduction to the mechanics of tensegrity structures," in Proceedings of the 40th IEEE Conference on Decision and Control, Orlando, FL, USA, 2001, pp. 4254-4259 vol.5.

[21] S. Djouadi, et al., "Active Control of Tensegrity Systems," Journal of Aerospace Engineering, vol. 11, pp. 37-44, 1998. 
Korkmaz et al, Determining Control Strategies for Damage Tolerance of an Active Tensegrity Structure, Engineering Structures, Volume 33, Issue 6, June 2011, Pages 1930-1939,

doi: http://dx.doi.org/10.1016/j.engstruct.2011.02.031

[22] W. Chan, et al., "Active vibration control of a three-stage tensegrity structure," presented at the SPIE 11th Annual International Symposium on Smart Structures and Materials, San Diego, California, USA, 2004.

[23] M. Ganesh Raja and S. Narayanan, "Active control of tensegrity structures under random excitation," Smart Materials and Structures, vol. 16, pp. 809-817, 2007.

[24] J. Averseng and B. Crosnier, "Static and dynamic robust control of tensegrity systems," Journal of The International Association for Shell and Spatial Structures, vol. 45, pp. 169-174, 2004.

[25] E. Fest, et al., "Active Tensegrity Structure," Journal of Structural Engineering, vol. 130, pp. 14541465, 2004.

[26] B. Adam and I. F. C. Smith, "Tensegrity Active Control: Multiobjective Approach," Journal of Computing in Civil Engineering, vol. 21, pp. 3-10, 2007.

[27] N. Bel Hadj Ali and I. F. C. Smith, "Dynamic behavior and vibration control of a tensegrity structure," International Journal of Solids and Structures, vol. 47, pp. 1285-1296, 2010.

[28] N. Kanchanasaratool and D. Williamson, "Modelling and control of class NSP tensegrity structures," International Journal of Control, vol. 75, pp. 123-139, 2002.

[29] A. G. Tibert and S. Pellegrino, "Deployable Tensegrity Reflectors for Small Satellites," Journal of Spacecraft and Rockets, vol. 39, pp. 701-709, 2002.

[30] C. Sultan, et al., "Linear dynamics of tensegrity structures," Engineering Structures, vol. 24, pp. 671-685, 2002.

[31] J.-P. Pinaud, et al., "Deployment of a class 2 tensegrity boom," in Smart Structures and Materials 2004: Smart Structures and Integrated Systems, 2004, pp. 155-162.

[32] A. Smaili and R. Motro, "Foldable/unfoldable curved tensegrity systems by finite mechanism activation," Journal of the International Association for Shell and Spatial Structures, vol. 48, pp. 153-160, 2007.

[33] S. Korkmaz, et al., "Configuration of Control System for Deployment and Damage Tolerance of a Tensegrity Bridge," submitted to: Advanced Engineering Informatics, 2011.

[34] A. G. Tibert and S. Pellegrino, "Deployable tensegrity masts," presented at the 44th AIAA/ASME/ASCE/AHS/ASC Structures, Structural Dynamics, and Materials Conference, Norfolk, VA, USA, 2003.

[35] C. Sultan and R. Skelton, "Deployment of tensegrity structures," International Journal of Solids and Structures, vol. 40, pp. 4637-4657, 2003.

[36] N. Bel Hadj Ali, et al., "Analysis of clustered tensegrity structures using a modified dynamic relaxation algorithm," International Journal of Solids and Structures, vol. 48, pp. 637-647, 2010.

[37] K. W. Moored and H. Bart-Smith, "Investigation of clustered actuation in tensegrity structures," International Journal of Solids and Structures, vol. 46, pp. 3272-3281, 2009.

[38] N. Ben Kahla and B. Moussa, "Effect of a Cable Rupture on Tensegrity Systems," International Journal of Space Structures, vol. 17, pp. 51-65, 2002.

[39] B. Adam and I. F. C. Smith, "Active tensegrity: A control framework for an adaptive civilengineering structure," Computers \& Structures, vol. 86, pp. 2215-2223, 2008.

[40] K. Abedi and B. Shekastehband, "Effect of member loss on the structural integrity of tensegrity systems," presented at the IASS Symposium 2009, Evolution and trends in Design, Analysis and Construction of Shell and Spatial Structures, Valencia (Spain), 2009.

[41] E. A. Coyle, et al., "Self-repair of embedded systems," Engineering Applications of Artificial Intelligence, vol. 17, pp. 1-9, 2004. 
Korkmaz et al, Determining Control Strategies for Damage Tolerance of an Active Tensegrity Structure, Engineering Structures, Volume 33, Issue 6, June 2011, Pages 1930-1939, doi: http://dx.doi.org/10.1016/j.engstruct.2011.02.031

[42] B. Raphael and I. F. C. Smith, "A direct stochastic algorithm for global search," Applied Mathematics and Computation, vol. 146, pp. 729-758, 2003.

[43] L. Rhode-Barbarigos, et al., "Designing tensegrity modules for pedestrian bridges," Engineering Structures, vol. 32, pp. 1158-1167, 2010.

[44] SIA, SIA 260 , Swiss Society of Engineers and Architects, 2003.

[45] A. Pugh, An Introduction to Tensegrity University of California Pr, 1976.

[46] SIA, SIA 261, Swiss Society of Engineers and Architects, 2003.

[47] M. Barnes, "Form Finding and Analysis of Tension Structures by Dynamic Relaxation," International Journal of Space Structures, vol. 14, pp. 147-54, 1999.

This work is licensed under a Creative Commons Attribution-NonCommercial-NoDerivatives 4.0 International License

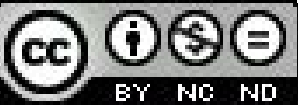

